\title{
Biometry and Genetics.
}

PROF. RAYMOND PEARL and his students continue to make important contributions to the biology of man and other organisms on a statistical basis. In a recent paper (Pearl and Bacon, Johns Hopkins Hospital Reports, vol. xxi. Fasc. iii.) an analysis is made of the relation of the relative size of heart, liver, spleen, and kidneys to tuberculosis. The data were derived from I34I autopsies in which there were tubercular lesions. Six indices for the relative weights of the above organs were used as the basis of statistical investigation in relation to age, sex, race, and cause of death. It is shown that the relative weights of liver and heart, and heart and spleen change progressively during life; also that in cases of fatal tuberculosis the absolute weight of the heart is less and of the spleen greater than normal, probably because these changes are brought about by the disease. Curves of age show that when tuberculosis alone is fatal it kills at comparatively early ages. Many other interesting facts are brought out in this statistical study.

In "dry" America, experiments with alcohol have a particular interest. Stockard has shown with guinea-pigs and Pearl with fowls that individuals which throughout life received daily doses of alcohol by inhalation are much longer-lived than their untreated sibs. In a recent note (Amer. Journ. Hygiene, vol. ii. No. 4) Prof. Pearl points out that the actuarial data of insurance companies, which are generally supposed to show that the consumption of alcohol in man in any quantity shortens life, are practically worthless. From 1569 family history records carefully collected in the vicinity of Baltimore, he concludes that while heavy or steady drinking lowers the expectation of life, the moderate or occasional consumption of alcohol has no such effect on either sex.

In experimental studies on the duration of life in Drosophila (Pearl and Parker, Amer. Naturalist, vols. $55,56)$ the authors compare the percentage of survivals at successive ages with the corresponding curve for man. A day in the life of a fruit-fly corresponds roughly with a year in the life of a man. Large numbers of flies of different stocks were bred under carefully standardised conditions. The length of the imaginal life was noted and the results compared with the statistics for man, beginning at the age of fifteen years. Fundamentally similar curves are obtained in the two cases. In Drosophila it is shown that longwinged flies have two or three times as great an expectation of life at any age as short-winged flies, and that other hereditary differences in duration of life also occur. The death-rates generally increase steadily with advancing age. The mortality curve for Drosophila is then compared with that for modern man and for the population of the Roman provinces in Africa about the beginning of the Christian era (from data of MacDonnell, Biometrika, I9I3). The Drosophila curve generally runs intermediate between these two. The modern curve of human mortality is diverted from the normal by the prolongation of life of many of the less rugged by measures of public health and sanitation.

By selection and inbreeding from Drosophila stocks it was possible to isolate strains showing large differences both in mean duration of life and in the form of the mortality distributions, while in inbred lines the genetic differences remained constant for ten to twentyfive generations. It was shown that occasional etherisation of the flies has no appreciable effect in lessening their duration of life. There is some evidence that in crosses, duration of life may segregate like a Mendelian character. A pedigree indicating something of the same kind in man is presented by
Pearl (Amer. Journ. Hygiene, vol. ii. No. 3). In the father's family only io per cent. survived to the age of fifty years, in the mother's family 75 per cent. reached that age, and in the offspring 87.5 per cent.

Using too births/deaths as a "vital index," Pearl and Burger (Proc. Nat. Acad. Sci. vol. 8, No. 4) plot the curve for this index for England and Wales in the years I 838-I920, from statistics in the Annual Reports of the Registrar-General. This ratio shows a slow but extremely steady increase until I9I4, with only two slight fluctuations caused by influenza epidemics in 1847 and $x 890$. The birth-rate in the meantime showed a slow increase until about 1878 , then a more rapid decrease until $19 \mathrm{I} 4$, and a marked recovery since the war. Thus while in the year I838-39 the number of births for each death was I.4, in rg20 it was more than 2. The whole curve for the vital index shows a remarkably steady increment in the rate of population growth, with a high degree of regulation of death-rates to variations in the birth-rate. Measured by the criterion of the vital index, it is concluded that the population of England and Wales is "biologically more vigorous "than in $r 838$. But this merely means that its net rate of increase is greater, and takes no account of the differential character of the birth-rate. In another note in the same issue, Pearl considers the seasonal fluctuations in the vital index of the population, based on the same data, and finds that in each year it has its lowest value in the winter quarter (ending March 3I), and its highest value in the summer quarter. In other words, in the winter months the birth incidence is relatively low and the death incidence relatively high, as might be expected.

That density of population influences fecundity was formerly shown for fowls; and similar results have now been obtained for Drosophila (Pearl and Parker, Proc. Nat. Acad. Sci. vol. 8, No. 7). The rate of reproduction of this fly is shown experimentally to vary inversely with the density of population. This is the converse of Farr's law that the death-rate varies directly with density of population. It is suggested that the world - wide increase in density of population may account for the general decline in birthrates which has taken place in the last forty years. The subject is one which deserves further investigation.

A hexadactylous Norwegian family in which the postaxial digits (little fingers and toes) are double, is described by Aslaug Sverdrup (Joum. Genetics, vol. xii. No. 3). The condition is traced through six generations, and two types of polydactylism are recognised. In type A one finger, usually the fifth, is duplicated, while in type B the sixth finger is represented by a small attached appendage. Both these types are already well known. The condition behaves in general as a dominant character, but in one line of the family, showing chiefly the A-type, there is an excess, and in another, showing only the B-type, a deficiency of polydactyls. Moreover, an A-type individual may have either A- or B-type offspring, whereas B-types cannot produce A-types. It is concluded that the B-type is probably determined by a single Mendelian factor with sometimes a failure of dominance, while the A-type is probably due to cumulative factors. The A-type of polydactyly is sometimes accompanied in this family by a form of brachydactyly due to shortening of certain metacarpal bones, but also in some cases to short phalanges. Such papers on the inheritance of human abnormalities are important in their recognition of the necessity for accurate and detailed observations.

In a study of the inheritance of patching in the flower of the sweet pea Prof. Punnett (Journ. Genetics, 
vol. 2 , No. 3) introduces facts which cannot be explained on the ordinary Mendelian basis. The sweet pea Duke of Westminster sometimes has on the wings a larger or smaller patch of purplish pink. Such patched plants give normal, red, and patched offspring in varying proportions. Certain branches of "patched " plants are sometimes normal. The seeds from such normal branches show no constant genetic difference from the rest of the plant, nor was any evidence obtained that the normal, patched, and red flowers on a patched plant differed from one another genetically. There is no indication of genetic differentiation in the germplasm of different parts of the plant. Nevertheless, patched plants are not apparently all alike. As in striped Mirabilis, the pair of colour characters may behave either as a segregating Mendelian pair or form a mosaic. There is no sufficient explanation of this mosaic condition at the present time, but it represents a condition differing distinctly from ordinary Mendelian behaviour.
In a second paper on the inheritance of characters in some of the many rice varieties, Mr. F. R. Parnell, with the assistance of Messrs. G. N. R. Ayyanger, K. Ramiah and C. R. S. Ayyangar (Mem. Dept. Agr. India, Botany, vol. xi. No. 8), deals with the colours of glumes and grain, also with dwarfing and with shape of grain. The dwarf variety differs very markedly from the type, but behaves as a simple recessive. A result of economic importance is that the weight of the grain varies with the shape. The hereditary behaviour of a number of colour factors is analysed. Another genetic paper of economic value is a study of certain forms of cotton by Mr. Ram Prasad (Agric. Inst. Pusa. Bull. No. I37). Long fibre is considered to be a dominant character in cotton. Some evidence is obtained that long fibre is correlated with long stigma, plants with short lint having shorter-styles. If this is the case it would enable roguing of undesirable plants producing short lint to take place much earlier than would otherwise be possible.

\section{Norway and Iceland: An Interesting Contrast.}

NORWAY has many interesting features to a visitor with scientific and technical tastes. The ubiquity of electricity generated from waterpower has often been the subject of comment. The peculiar formation of the high tablelands, with lakes at heights of I000-3000 feet, constantly renewed by water from the snows above, is favourable to hydroelectric supply. The potential value of the waterpower of Norway has been assessed at I 5,00o, ooo h.p., of which about one million is at present in use.

The mountainous nature of the country has other interesting consequences. One curious result is that communication between valleys is often less easy in summer than in winter, when roads and passes become covered with deep snow and can be traversed by ski and sleigh. The nature of the country has developed isolated scattered communities with pastoral tastes and special local industries, such as the hand-woven fabrics for which Norway is famous.

The climate has much in common with that of England. Bergen is notorious for its rainfall, and the humid atmosphere is doubtless responsible for the luxuriant growth of trees, springing in masses out of the bare rock lining the fiords in a manner that seems to invite study by experts in forestry. The use of timber in Norway is universal. Buildings are almost invariably of wood, and the humbler cottages are roofed with turf, which seems to thrive in the moist atmosphere. In mountainous Norway grass is scarce. Hence the custom of sending cattle up to the mountain "sæters" in the summer, so that the grass at the level of the fiord can be stored in summer-time. This cut grass is hung up to dry on horizontal lengths of wire. Possibly British farmers could take a hint from this practice, as crops in this country are often spoiled by rain.

Geologically the great tablelands of Norway, with their stretches of perpetual snow at relatively low level, and their vast glaciers (the largest in Europe with the exception of those in Iceland) are of great interest. It is a strange sight to find these great glaciers descending right down to the level of the fiord, as happens, for example, at Fjaerland.

Iceland furnishes some interesting contrasts to Norway. The climate is more stable and less like that of Britain. Whereas in Norway trees are everywhere, in Iceland there are practically none. Hence we find a new material for buildings of the better class-corrugated iron! Grass is also scarce, and
Iceland is one of the few countries where rabbits will not thrive. The scenery, though almost destitute of verdure, is not monotonous and has a charm of its own. It consists mainly of alternations of rock, lava, and sand, with, on the lower slopes of mountains, stretches of moss. All vary remarkably in colour. Rocks are black, brown, purple, and occasionally bright red. Sand may have any tint from yellow to black. Amazing changes in colour, difficult to explain and offering an interesting study to the physicist, occur as the sun sets. A curious feature is the astonishing brilliancy of the setting sun, exceeding by far that usual in England. The pools of molten lava also afford a field for study. Their position is indicated by a sulphur-yellow crust, but the upper liquid contents are often bright blue, changing to scarlet at a lower level. Hecla, by the way, although the mountain best known to English readers, is by no means the best example of volcanic action, and is a comparatively inconspicuous mountain.

Ice and snow, usually not far distant in Norway, are universal on the higher mountains of Iceland, and the blanket of ice and snow creeping over the edges of precipices forms an important element in the general scheme of coloration.

In one respect Iceland and Norway seem to be much alike - in the hospitality accorded to the English visitor. In Norway, especially when one leaves the beaten track, one is conscious of an atmosphere very different from that in many hotels in Europe. In Iceland, once he leaves the capital, the traveller finds practically no hotels, but he can rely on the generous hospitality of the districts visited. Ponies are the usual mode of conveyance. It is stated that the import of horses is forbidden, as the Icelandic Government desires to keep the strain of ponies pure.

In Norway the present writer was impressed by the high general level of education. One could converse on equal terms with persons of all degrees, and learn facts of interest about the country. English is a compulsory language in the schools, and is often spoken with considerable facility. Even in Iceland, it appears, English is spoken more frequently than might be expected. Here again there is a high level of education, but owing to the remoteness of the island some strange conceptions of England prevail.

In Iceland, as in Norway, a variant of Danish is NO. 2789 , VOL. I I I] 